\title{
This is a wakeup call: Alarm clock headache
}

\author{
Ayush Dubey ${ }^{*}$ and Shubham Dubey ${ }^{2}$ \\ ${ }^{1}$ Department of Medicine, RD Gardi Medical College, Surasa, Bhopal (MP), India \\ ${ }^{2}$ Department of Neurology, Meenakshi Medical College Hospital and Research Institute, Kanchipuram, India
}

\begin{abstract}
Hypnic headache, also known as alarm clock headache is one of the rare subtypes of primary headaches described in literature. It is a typical nocturnal headache which only occurs in sleep and generally affects elderly population. It needs to be differentiated from the other common primary headaches as the therapeutic options for it are very different from the other common headaches. The description is only through case reports and small case series. A review of this less known entity is discussed here.
\end{abstract}

Abbreviations: HH: Hypnic Headache; ICHD: International
Classification of Headache Disorders

\section{Introduction}

Hypnic headache $[\mathrm{HH}]$ is one of the primary headache disorders first described by Raskin in 1988 [1] and subsequently included in the International Classification of Headache Disorders (ICHD-II) [2]. It occurs exclusively during sleep and affects population generally over 50 years of age. It is still poorly understood and rarely diagnosed. It is known as alarm clock headache or clockwise headache [3] as it always occurs over same time of night (generally 2-4 AM) and wakes up the patient from sleep. The pattern of headache needs to be differentiated from other common primary headaches like migraine and cluster headache before start of therapy.

\section{Clinical presentation}

International Classification of headache disorders has revised the diagnostic criteria for HH in their 3rd version in 2018 [Table 1] [4]. The headache is described as mild to moderate and localized, mainly bilateral but sometimes unilateral with dull character in majority of cases but can also be throbbing or stabbing type. The typical duration of an attack is at least $15 \mathrm{~min}$ and averages about $80 \mathrm{~min}$ but can last up to $6 \mathrm{~h}$. The frequency per night is average 1 to 2 attacks, with a mean frequency per month of about 20-25. Most patients display motor behaviour when awakening with headache at night, such as reading, eating, drinking, watching TV, listening to radio, walking around, taking a hot shower, or cooling the head, but these symptoms never reach the level of agitation or restlessness that can be observed in cluster headache attacks [5]. The natural course of the disorder is unknown. Some authors have classified $\mathrm{HH}$ into two different forms, chronic and

Table 1. International Headache Society diagnostic criteria for hypnic headache

\begin{tabular}{|l|l|}
\hline A & Recurrent headache attacks fulfilling criteria B-E \\
\hline B & Developing only during sleep, and causing wakening \\
\hline C & Occurring on 10 days/month for $>3$ months \\
\hline D & Lasting from 15 minutes up to four hours after waking \\
\hline E & No cranial autonomic symptoms or restlessness \\
\hline F & Not better accounted for by another ICHD-3 diagnosis \\
\hline
\end{tabular}

episodic form. The episodic form is further subdivided into two types, episodic with no recurrence, and relapsing and remitting variety [6].

\section{Pathophysiology}

The pathophysiology of $\mathrm{HH}$ is still unclear. It was previously suggested that $\mathrm{HH}$ attacks might be associated with REM sleep, based on polysomnographic reports [7]. But recent studies have contradicted this assumption.

A different hypothesis suggested a crucial role of obstructive sleep apnea in the underlying pathophysiology of $\mathrm{HH}$. Although all sleep studies in HH showed an increased apnea/hypopnea-index, the onset of the recorded $\mathrm{HH}$ attacks was not temporally correlated with the observed drop of oxygen saturation [8]. Presumably, the increased prevalence of obstructive sleep apnea is related to the age of the population rather than to the disease itself [9].

The clinical features of $\mathrm{HH}$, with its chronobiological presentation, lead to the hypothesis of a hypothalamic alteration in $\mathrm{HH}$. The hypothalamus is involved in regulation of the sleep-wake cycle as well as in central pain processing [10]. Structural imaging of $14 \mathrm{HH}$ patients using voxel-based morphometry (VBM) showed a decrease of gray matter within the posterior hypothalamus [11]. Changes of trigeminal pain processing in terms of central facilitation and alteration of habituation, which were commonly observed in other primary headache disorders such as migraine, were not detected in $\mathrm{HH}$ [12]. Further investigation of $\mathrm{HH}$ pathophysiology may offer a better understanding of the disease and may provide new treatment approaches in the future.

\section{Diagnosis}

HH can be diagnosed only when other primary headache disorders that may also present with sleep related headache attacks are ruled out.

${ }^{*}$ Correspondence to: Ayush Dubey, Department of Medicine, RD Gardi Medical College, Surasa, Bhopal (MP), India, E-mail: ayushdubey2@yahoo.co.in

Key words: Alarm clock headache, Hypnic headache

Received: December 10, 2018; Accepted: December 19, 2018; Published: December 24, 2018 
The International Classification of Sleep Disorders classifies besides $\mathrm{HH}$ a few other primary headaches as so-called sleep-related headaches, which are cluster headache, chronic paroxysmal hemicrania and migraine [13]. Sleep independent headache attacks also occur in most cluster headache patients, which helps to differentiate cluster headache from $\mathrm{HH}$. Other clinical features for differentiation are distinct trigemino-autonomic features and headache-accompanied restlessness that can be observed only in cluster headache. In Chronic paroxysmal hemicranias, along with ipsilateral trigemino-autonomic symptoms in regard to the headache side, duration of headache is usually shorter than in $\mathrm{HH}$ attacks (i.e. 2-30 minutes). Headache frequencies above five per day are typically seen in chronic paroxysmal hemicrania. In migraine, on waking up, patient generally tries to keep immobile in contrast to the physical activity seen in HH. Also, the headache does not strictly occur only at the time as seen in HH. It is a common clinical observation that migraine attacks often occur during night sleep and upon awakening. If a patient has headache attacks fulfilling ICHD criteria for other primary headaches such as those mentioned above, these headache entities should be considered first before diagnosing a patient with $\mathrm{HH}$, because these headache disorders are much more common than $\mathrm{HH}$.

It is important to differentiate $\mathrm{HH}$ from two other confusing conditions:

a) The exploding head syndrome [14] is the sensation for few seconds that an explosive noise has occurred in the head, which wakens the patient from sleep. These also occur in patients more than 50 years of age but the occurrence of this in all sleep stages and the hearing of waking sound rather than headache differentiates it from $\mathrm{HH}$.

b) Turtle headache [15] occurs in morning after awakening and going back to sleep. The headache is bilateral and only occurs if the patient pulls the bed covers over his or her head, or retracts his or her head under the blankets, like a turtle retreating under its carapace. It has been suggested that hypoxia is the underlying cause and so this should be regarded as a symptomatic headache.

Investigatory modalities include brain imaging to rule out secondary causes of headache such as brain tumours. 24-hour blood pressure monitoring should be done ideally in all such cases to rule out nocturnal arterial hypertension. Polysomnographic study may be done to look for sleep apnoea.

\section{Treatment}

As data regarding $\mathrm{HH}$ is scarce, no controlled trials for the treatment of $\mathrm{HH}$ are found. Acute therapy for $\mathrm{HH}$ is generally ineffective. Oxygen therapy and drugs such as sumatriptan which forms the mainstay of treatment in cluster headache are not effective in $\mathrm{HH}$ while other drugs like acetylsalicylic acid and acetaminophen have got a very limited action in cessation of acute headache.

As regards to preventive therapy, lithium is found to be most effective as the first line therapy [1]. It interacts with the pain modulating system possibly involved in $\mathrm{HH}$ and seems to increase indirectly nocturnal production of melatonin. Moreover, lithium may exert an enhancing effect on cerebral serotonin functions. Lithium carbonate can be initiated at $300 \mathrm{mg}$ at night and increased to $600 \mathrm{mg}$ after 1 or 2 weeks if necessary [1]. Poor tolerability to lithium is not rare, mainly in elderly patients. Renal and thyroid function should be assessed before initiating therapy, and periodically during treatment. Serum lithium concentrations should be monitored as well to avoid toxicity. Side effects include tremor, diarrhoea, increased thirst and polyuria. Many other agents that have been reported to effectively treat $\mathrm{HH}$ include bedtime doses of caffeine (40-60 mg tablet, or as a cup of coffee), indomethacin, flunarizine, tricyclic antidepressants, verapamil, prednisone, topiramate, gabapentin, melatonin, benzodiazepines, pregabalin and acetazolamide.

Indomethacin, which is the mainstay of treatment in chronic paroxysmal hemicranias, may be helpful in those patients whose $\mathrm{HH}$ attacks are unilateral [16]. It was shown to be effective in extremely variable doses, ranging from $25 \mathrm{mg}$ to $150 \mathrm{mg} /$ day. Some patients who responded to indomethacin before bedtime developed daytime headaches, which resolved after indomethacin was discontinued. This phenomenon was termed as "the paradox of indomethacin", whose most prominent side effect and reason for discontinuation (headache) is the very symptom for which it provides a remarkable therapeutic efficacy [16]. Hence, a practical approach can be a course of 300-600 mg lithium to be tried first, on some instances in association with caffeine and/or melatonin, followed, 3-4 months later, by tapering. If headache recurs during tapering, a longer duration of therapy may be needed. The treatment with caffeine and in particular with melatonin alone did not yield robust evidence to recommend their use as single preventive agents. Their association with the recommended medications (i.e. lithium and indomethacin) seems to produce an additional overall therapeutic efficacy. If lithium treatment does not provide a significant response, as second line approach indomethacin can be commenced, at a dose ranging from 25 to $75 \mathrm{mg}$ at bedtime; caffeine can also be tried, alone or in combination with indomethacin. If these treatments prove to be ineffective, other medications, such as verapamil, flunarizine or topiramate, can be administered. These drugs are also recommended when lithium and indomethacin are contraindicated or are related to significant side effects.

\section{Conclusion}

Hypnic headache is one of the rare primary headache disorders. It should be suspected in elderly patients presenting with headaches awakening them from sleep on most days of a month. It should be differentiated from the more common primary headaches and secondary causes of headaches such as intracranial space occupying lesions by means of meticulous history, examination and investigations. Once labelled as hypnic headache, therapy should be started with a keen eye on the response. Due to scarcity of literature on this entity, further trials are needed to come up with more therapeutic options in future.

\section{References}

1. Raskin NH (1988) The hypnic headache syndrome. Headache 28: 534-536. [Crossref]

2. Headache Classification Subcommittee of the International Headache Society (2004) The International Classification of Headache Disorders, 2nd edn. Cephalalgia 24 (Suppl 1):1-160

3. Newman LC, Lipton RB, Solomon S (1990) The hypnic headache syndrome: a benign headache disorder of the elderly. Neurology 40: 1904-1905. [Crossref]

4. Headache Classification Subcommittee of the International Headache Society (IHS) The International Classification of Headache Disorders, 3rd edn. Cephalalgia 2018, Vol. 38(1) 1-211

5. Evers S, Goadsby PJ (2003) Hypnic headache: clinical features, pathophysiology, and treatment. Neurology 60: 905-909. [Crossref]

6. Lisotto C, Mainardi F, Maggioni F, Zanchin G (2004) Episodic hypnic headache? Cephalalgia 24: 681-685. [Crossref]

7. Manni R, Sances G, Terzaghi M, Ghiotto N, Nappi G (2004) Hypnic headache: PSG evidence of both REM- and NREM-related attacks. Neurology 62: 1411-1413. [Crossref] 
8. Holle D, Naegel S, Krebs S, Katsarava Z, Diener HC, et al. (2010) Clinical characteristics and therapeutic options in hypnic headache. Cephalalgia 30: 1435-1442. [Crossref]

9. Young T, Peppard PE, Gottlieb DJ (2002) Epidemiology of obstructive sleep apnea: a population health perspective. Am J Respir Crit Care Med 165: 1217 1239. [Crossref]

10. Settle M (2000) The hypothalamus. Neonatal Netw 19: 9-14. [Crossref]

11. Holle D, Naegel S, Krebs S, Gaul C, Gizewski E, et al. (2011) Hypothalamic gray matter volume loss in hypnic headache. Ann Neurol 69: 533-539. [Crossref]
12. Holle D, Gaul C, Krebs S, Naegel S, Diener HC, et al. (2011) Nociceptive blink reflex and pain-related evoked potentials in hypnic headache. Cephalalgia 31: 1181-8. [Crossref]

13. International Classification of Sleep Disorders, 2nd ed. Diagnostic and coding manual. Westchester, IL: American Academy of Sleep Medicine, 2005.

14. Armstrong-Jones R (1920) Snapping of the brain. Lancet 720

15. Gilbert GJ (1972) Hypoxia and bedcovers. JAMA 221: 1165-1166. [Crossref]

16. Dodick DW, Jones JM, Capobianco DJ (2000) Hypnic headache: another indomethacinresponsive headache syndrome? Headache 40: 830-835. [Crossref]

Copyright: @2018 Dubey A. This is an open-access article distributed under the terms of the Creative Commons Attribution License, which permits unrestricted use, distribution, and reproduction in any medium, provided the original author and source are credited. 